\title{
Agenesis of the corpus callosum with Probst bundles owing to haploinsufficiency for a gene in an $8 \mathrm{cM}$ region of $6 \mathrm{q} 25$
}

\author{
Barbara Pirola, Livio Bortotto, Sabrina Giglio, Emanuela Piovan, Augusta Janes, \\ Renzo Guerrini, Orsetta Zuffardi
}

Biologia Generale e Genetica Medica, Università di Pavia,

Via Forlanini 14, 27100

Pavia, Italy

B Pirola

S Giglio

O Zuffardi

Istituto

Immunotrasfusionale and Divisione di

Neonatologia, Azienda

Ospedaliera S Maria

della Misericordia,

Udine, Italy

L Bortotto

E Piovan

A Janes

IRCCS Stella Maris,

Pisa, Italy

R Guerrini

\section{Laboratorio di}

Citogenetica, Ospedale

S Raffaele, Milano,

Italy

O Zuffardi

Correspondence to: Dr Zuffardi.

Received 4 February 1998 Revised version accepted for publication 8 May 1998

\begin{abstract}
Agenesis of the corpus callosum (ACC) is a relatively common brain abnormality resulting from developmental defects either limited to the structures leading to the proper formation of the corpus callosum or involving the embryo forebrain more generally. ACC is genetically heterogeneous with autosomal dominant, autosomal recessive, and $X$ linked inheritance and has also been reported in subjects with aneuploidies involving several chromosomes. Among them, distal 6q deletions have been consistently reported in association with ACC, suggesting that there is a gene in the deleted region whose haploinsufficiency impairs normal corpus callosum development. We have studied a child with ACC with Probst bundles and a deletion at 6 q25 of about $8 \mathrm{cM}$, from D6S1496 to D6S437. Probst bundles are the axons that should have formed the corpus callosum but, unable to cross the midline owing to absence of the massa commissuralis, they run longitudinally along the medial walls of the lateral ventricles from the frontal to the occipital lobes. Thus, their presence suggests that a gene located in the $6 \mathrm{q}$ deleted region is specifically involved in the formation of the massa commissuralis and that its haploinsufficiency leads to primary ACC. (F Med Genet 1998;35:1031-1033)
\end{abstract}

Keywords: agenesis of the corpus callosum; Probst bundles; 6q deletion

In reviewing the genetics of agenesis of the corpus callosum (ACC), Dobyns ${ }^{1}$ concluded that aneuploidies (deletion or duplication) for no less than 19 chromosome regions are consistently associated with ACC. Thus, all these regions are likely to harbour genes that act in a dominant way interfering, by haploinsufficiency or excessive dosage, with the development of the corpus callosum. We studied a child whose brain abnormalities were detected during routine prenatal echography. Cytogenetic analysis performed at birth showed an interstitial deletion around 6q25. Since haploinsufficiency for this region is consistently associated with ACC, ${ }^{1}$ we decided to define the deletion at the molecular level.

\section{Case report}

The female patient was born at 38 weeks of gestation to a primiparous, 33 year old, healthy woman and an unrelated, 41 year old, healthy father.

Fetal ultrasonography in the last trimester of gestation showed enlargement of the cerebral ventricles (hydrocephalus). Delivery was by caesarean section. Birth weight was $2600 \mathrm{~g}$ (3rd-10th centile), length was $47 \mathrm{~cm}$ (3rd-10th centile), and head circumference (OFC) was $32.5 \mathrm{~cm}(-2 \mathrm{SD})$. Apgar scores were 3 at one minute and 8 at five minutes. Dysmorphic features included dolichocephaly, high arched and cleft palate (occult submucous), low set ears of normal size, hands with relatively long distal phalanges, and an anteriorly placed anus. Marked muscular hypotonia was also noted which led, in conjunction with the cleft palate, to feeding problems which were overcome at 5 months.

The ocular fundi were normal. CT scan of the head showed ACC and dilatation of both lateral ventricles. At the age of 5 months the patient showed moderately delayed psychomotor development and mild lateral nystagmus. Magnetic resonance imaging (MRI) confirmed ACC and led to detection of Probst bundles (fig $1 \mathrm{~B}, \mathrm{C}, \mathrm{D}$ ). At the age of 9 months (fig $1 \mathrm{~A}$ ), her weight $(6200 \mathrm{~g})$ and height $(66 \mathrm{~cm})$ were below the 3rd centile; head circumference was $44 \mathrm{~cm}$ ( $~ 50$ th centile). Psychomotor retardation (mild to moderate), hypotonia, and nystagmus were still present.

\section{Cytogenetic and molecular studies}

Cytogenetic analysis of cultured peripheral lymphocytes was performed with standard high resolution techniques. QFQ and RBA banding (more than 550 bands) showed an unbalanced karyotype with an interstitial deletion of the long arm of chromosome 6 at the level of q25 (fig 2A).

Both parents had a normal karyotype. FISH $^{2}$ with a set of YACs covering the deleted region, selected according to the Genome Database (www-genome.wi.mit.edu/cgi-bin/ contig/phys_map) allowed the proximal and distal breakpoints to be identified. The results of the FISH analysis are summarised in table 1 and in fig $2 \mathrm{~B}, \mathrm{C}$.

The deletion of 8-9 cM extended from locus D6S1496 (154 cM) to D6S437 (162 cM). Accordingly, the final karyotype was: 46,XX,del(6) (q25.1q25.3) de novo. Parental origin of the deletion was determined by PCR 


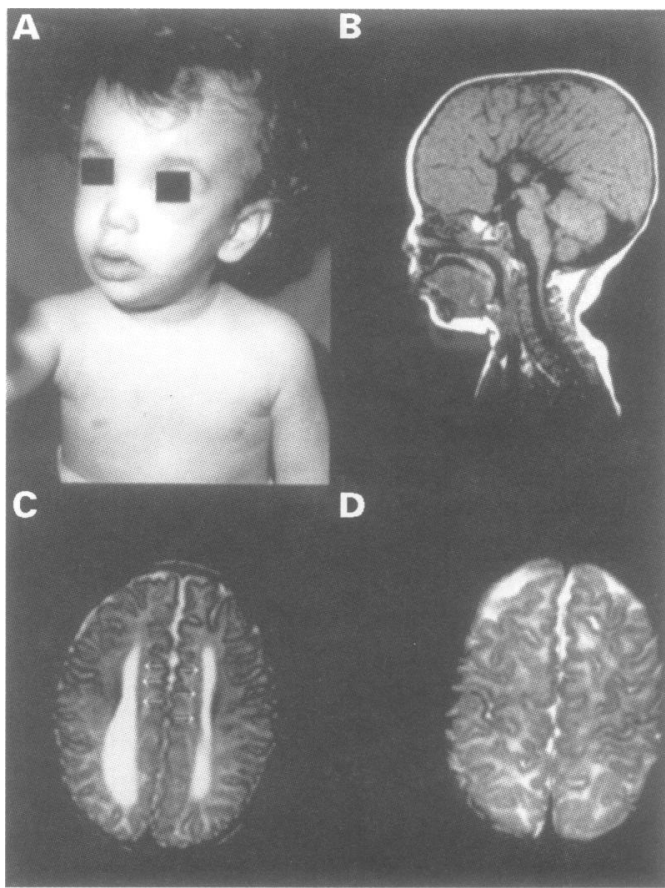

Figure 1 (A) The patient at the age of 9 months. (B) $T 1$ weighted sagittal image through the midline. The corpus callosum and the cingulate gyrus are absent. The medial hemispheric sulci are running all the way towards the third ventricles. (C) T2 weighted axial image showing dilatation of the atria and occipital horns of both lateral ventricles (colpocephaly) because of lack of the corpus callosum. Arrows indicate Probst bundles. (D) T2 weighted axial image showing a normal cortical gyral pattern.

analysis of CA repeats ${ }^{3}$ (fig 3A). Probe D6S1633, localised within the deleted region, detected a polymorphism informative for a paternal origin of the deletion. Paternity was confirmed by PCR analysis of CA repeats of loci D2S405 (fig 3B) and D15S1048.
Table 1 FISH results: locus copy number on the abnormal chromosome 6

\begin{tabular}{llll}
\hline Locus & $\begin{array}{l}\text { Map position } \\
(c M)\end{array}$ & YAC & Signal \\
\hline D6S472 & 133 & $970 \mathrm{A12}$ & + \\
D6S314 & 144 & $857 \mathrm{D} 11$ & + \\
D6S292 & 146 & $915 \mathrm{~F} 1$ & + \\
D6S311 & 148 & $800 \mathrm{H} 6$ & + \\
D6S1654 & 151 & $972 \mathrm{A3}$ & + \\
D6S1496 & 154 & $806 \mathrm{~B} 12$ & + \\
D6S440 & 155 & $767 \mathrm{~F} 3$ & - \\
D6S290 & 155 & $771 \mathrm{C} 12$ & - \\
D6S415 & 161 & $830 \mathrm{~B} 11$ & - \\
D6S437 & 162 & $845 \mathrm{F6}$ & +
\end{tabular}

+ and - refer to the presence or absence of FISH hybridisation signals on the abnormal chromosome 6 .

\section{Discussion}

Agenesis of the corpus callosum, either isolated or associated with other malformations, is among the most common developmental brain abnormalities. ${ }^{45}$ Embryological studies suggest that there are two primary and two secondary types of callosal abnormality. ${ }^{1}$ Primary forms include (1) defects in which axons form but are unable to cross the midline because the massa commissuralis is absent. In this case longitudinal fibres that should have formed the corpus callosum, known as Probst bundles, run longitudinally along the medial walls of the lateral ventricles from the frontal to occipital lobes; (2) defects in which the commissural axons or their parental cell bodies fail to form in the cerebral cortex.

Secondary callosal abnormalities include (1) absence of the corpus callosum associated with major malformations of the embryonic forebrain (such as encephaloceles and holoprosencephaly) originating before the formation of the anlage of the corpus callosum; (2) degeneration or atrophy of the corpus callosum, leading to its extreme thinning, which may be
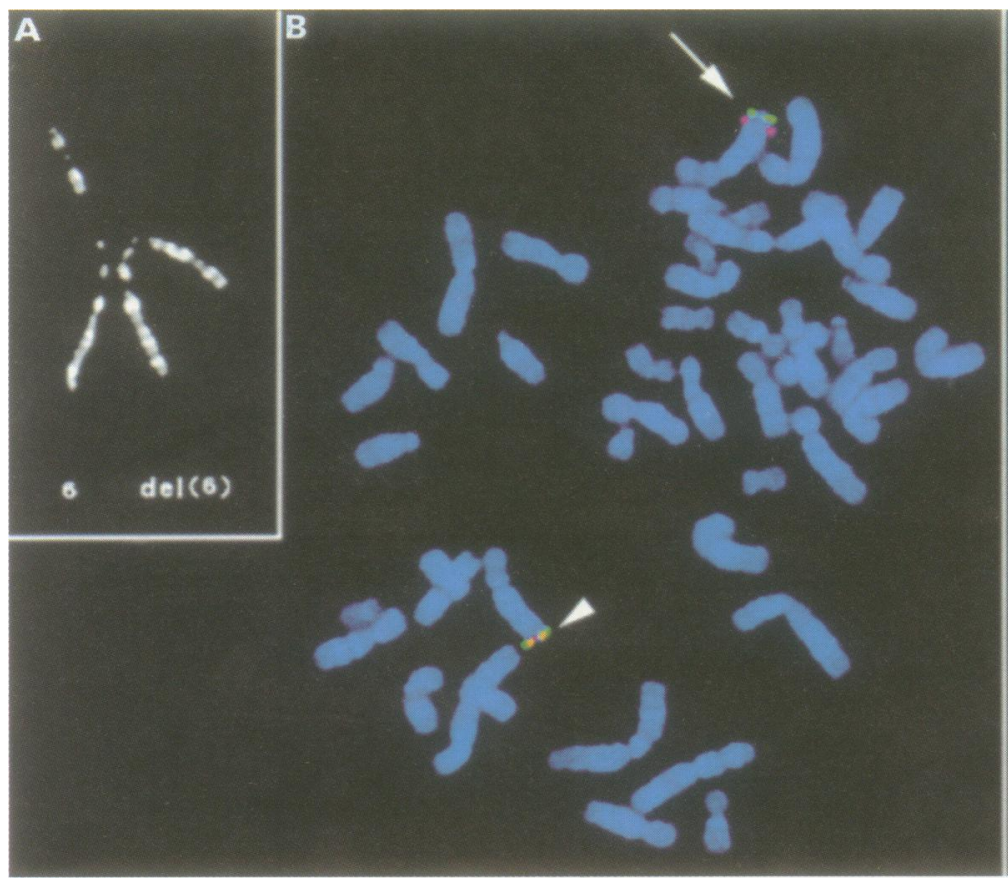

Figure 2 (A) Chromosomes 6 from the patient. (B) Metaphase from the patient after FISH with YAC $806 B 12$ (D6S1496, $154 \mathrm{cM}$ ) in red and with YAC 845F6 (D6S437, $162 \mathrm{cM}$ ) in green. Arrow indicates normal chromosome 6, arrowhead indicates the deleted one with fusion of colours. (C) Ideogram of the normal and the abnormal chromosomes 6. Colours refer to FISH hybridisation signals. 

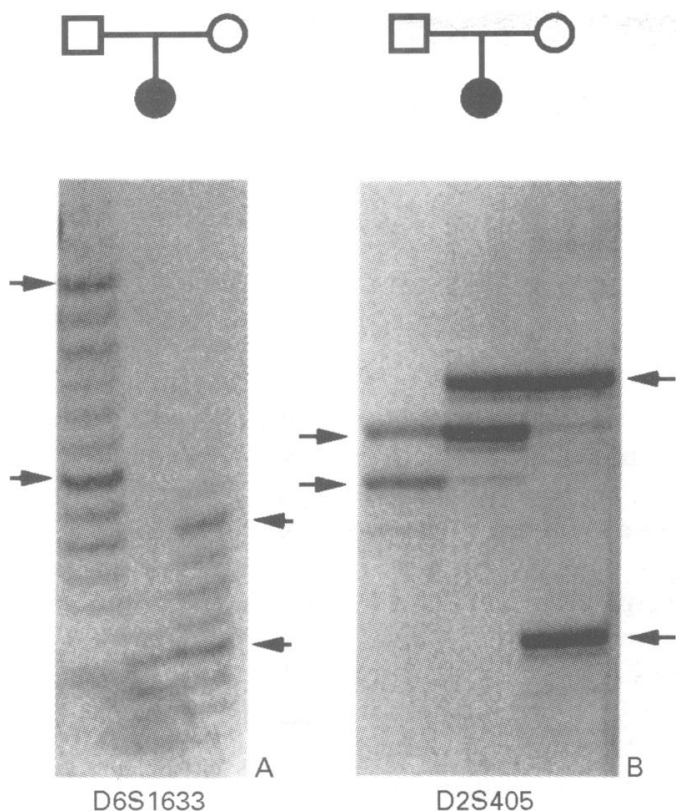

Figure 3 (A) PCR analysis of $C A$ repeats at locus D6S1633. The patient has only one allele, inherited from her mother. (B) PCR analysis of $C A$ repeats at locus D2S405. The patient is heterozygous having received one allele from each parent. Arrows indicate paternal and maternal alleles.

mistaken for true agenesis. ACC has been observed in families with autosomal dominant, autosomal recessive, and $\mathrm{X}$ linked inheritance, ${ }^{16}$ but it is also associated with several chromosome rearrangements including 6q distal deletions. ${ }^{1}$ The few genes involved in the development of the corpus callosum that have been isolated interfere with brain development in general since their mutations lead to ACC associated with malformations such as lissencephly and holoprosencephaly. ${ }^{7}$ At present, L1CAM is the only gene whose mutations, generally responsible for a wide spectrum of neurological abnormalities, result in primary ACC without other congenital anomalies in a few males. ${ }^{9}$ This study suggests that in the $6 \mathrm{q}$ region deleted in our patient a gene is located whose haploinsufficiency results in primary ACC. Other published reports confirm this relationship. ACC was found at necropsy in a 21 week male fetus with $\operatorname{del}(6)\left(\right.$ q23-qter) ${ }^{10}$ and, using transfontanellar ultrasound, in a newborn male with del(6)(q25.1-q27). ${ }^{11}$ Similarly, ACC was found on studying the brains of two newborns, both with a $\mathrm{r}(6)$ (cases 1 and $4^{12}$ ), in which part of the distal short and long arms had probably been lost in the formation of the ring. No ACC was reported in case 2 of Narahara $e t ~ a l^{13}$ with a $6 \mathrm{q}$ deletion identical to that of our case. This indicates either that the two deletions are different in spite of the same cytogenetic interpretation or that ACC has incomplete penetrance. In all these cases other malformations were reported, possibly linked to haploinsufficiency for other genes in the deleted region. We thus defined a 8-9 cM region in $6 \mathrm{q} 25$ in which a gene responsible for the development of the corpus callosum should be located. The corresponding physical distance cannot be precisely estimated since the deleted region is not covered by a complete YAC contig. The longitudinal bundles of Probst represent axons which, unable to cross the interhemispheric fissure, have diverted $90^{\circ}$ posteriorly to run parallel to the interhemispheric fissure, medial to the medial walls of the lateral ventricles of their hemisphere of origin. ${ }^{14}{ }^{15}$ The bundles of Probst can therefore be considered a marker for distinguishing true callosal agenesis from secondary callosal hypoplasia or atrophy. Their presence could indicate that in our patient the ACC gene located in the deleted region is specifically involved in the formation of the massa commissuralis, since its haploinsufficiency would make the axons unable to cross the midline. Since there are no studies on the parental origin of the other cases with del(6q) and ACC, we do not know if the ACC-6q gene is imprinted as is the case for the transient neonatal diabetes gene in $6 \mathrm{q} 22-\mathrm{q} 23 .{ }^{16}$

We wish to thank Professor M Fraccaro, Pavia, for helpful discussion.

1 Dobyns WB. Absence makes the search grow longer. $\operatorname{Am} \mathcal{F}$ Hum Genet 1996;58:7-16.

2 Carrozzo R, Arrigo G, Rossi E, et al. Multiple congenital anomalies, brain hypomyelinization and ocular albinism in a female with $\operatorname{dup}(\mathrm{X})$ (pter-q24::q21.32-qter) and random $\mathrm{X}$ inactivation. Am $\mathcal{F}$ Med Genet 1997;72:329-34.

3 Floridia G, Piantanida M, Minelli A, et al. The same molecular mechanism at the maternal meiosis I produces mono- and dicentric $8 \mathrm{p}$ duplications. Am $\mathcal{f}$ Hum Genet 1996;58:785-96.

4 Myrianthopoulos NC. Epidemiology of central nervous system malformations. In: Vinken PJ, Bruyn GW, Myrianthopoulos NC, eds. Congenital malformations of the brain and skull. Part I. Amsterdam: North-Holland, 1977:139-71.

5 Jeret JS, Serur D, Wisniewski K, Fisch C. Frequency of agenesis of the corpus callosum in the developmentally agenesis of the corpus callosum in the developmentally
disabled population as determined by computerized disabled population as determined by
tomography. Pediatr Neurosci $1985 ; 12: 101-3$.

6 Inbar D, Halpern GJ, Weitz R, Sadeh M, Shohat M. Agenesis of the corpus callosum in a mother and son. Am $\mathcal{F} M e d$ Genet 1997;69:152-4.

7 Reiner O, Carrozzo R, Shen Y, et al. Isolation of a Miller-Dieker lissencephaly gene containing $G$ protein beta-subunit-like repeats. Nature 1993;364:717-21.

8 Roessler E, Belloni E, Gaudenz K, et al. Mutations in the human sonic hedgehog gene cause holoprosencephaly. Nat Genet 1996;14:357-60.

9 Fransen E, Van Camp G, Vits L, Willems PJ. L1-associated diseases: clinical geneticists divide, molecular geneticicts
unite. Hum Mol Genet 1997;6:1625-32.

10 Shen-Schwarz S, Hill LM, Surti U, Marchese S. Deletion of terminal portion of $6 \mathrm{q}$ : report of a case with unusual malterminal portion of $6 \mathrm{q}$ : report of a case with

11 Rubstov N, Senger G, Kuzcera $\mathrm{H}$, et al. Interstitial deletion of chromosome 6q: precise definition of the breakpoints by microdissection, DNA amplification, and reverse painting. Hum Genet 1996;97:705-9.

12 Peeden JN, Scarbrough P, Taysi K, et al. Ring chromosome 6: variability in phenotypic expression. Am $\mathcal{f}$ Med Genet 1983;16:563-73.

13 Narahara K, Tsuji K, Yokoyama Y, et al. Specification of small distal $6 \mathrm{q}$ deletions in two patients by gene dosage and in situ hybridization study of plasmingen fucosidase 2. Am ₹ Med Genet 1991;40:348-53.

14 Probst PB. A defect in the anterior part of the corpus callosum simulating a tumor. Neuroradiology 1974;7:205-8.

15 Barkovich AJ, Lyon G, Evrard P. Formation, maturation and Barkovich AJ, Lyon G, Evrard P. Formation, maturatio
disorders of white matter. AFNR 1992;13:447-61.

16 Temple IK, Gardner RJ, Robinson DO, et al. Further evidence for an imprinted gene for neonatal diabetes localised to chromosome 6q22-q23. Hum Mol Genet 1996;5: 1117-21 